\title{
Irrigação de alface
}

\author{
SALIM SIMAO \\ Livre-docente da 12a. Cadeira (Horticultura) \\ Escola Superior de Agricultura "Luiz de Querroz" \\ Universidade de S. Paulo - Piracicaba
}

INDICE

$\begin{array}{llllllllll}\text { Introdução } & \ldots & \ldots & \ldots & \ldots & \ldots & \ldots & \ldots & \ldots & \ldots\end{array}$

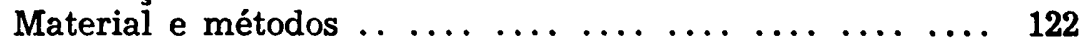

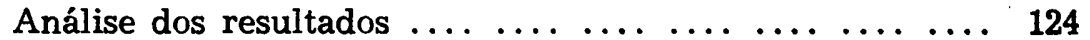

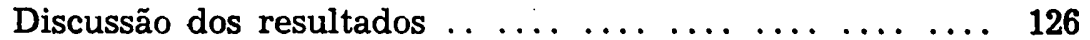

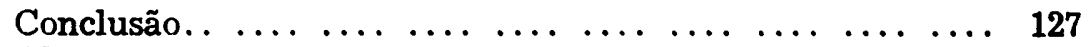

$\begin{array}{llllllllllll}\text { Abstract } \ldots & \ldots & \ldots & \ldots & \ldots & \ldots & \ldots & \ldots & \ldots & \ldots & \ldots & \ldots\end{array}$

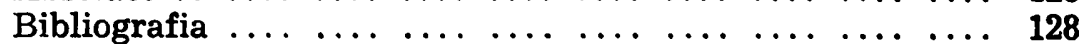




\section{INTRODUÇÃO}

A quantidade de água no solo é de grande importância no desenvolvimento das hortaliças. E' esta uma das razões pelas quais se procuram estabelecer hortas nos lugares de baixadas, próximos de cursos de água, onde os terrenos são sempre mais frescos que os das regiōes mais elevadas.

A alface é, dentre as hortaliças, uma das que maior quantidade de água retiram do solo.

ANDERSON (1939) procurou determinar a quantidade de água e umidade contida no solo, em relação ao crescimento da alface. KNO'TT (1951) diz que, quando possivel, em cada irrigação devemos trazer o solo para o "field capacity" ou estado de saturação. Os estudos revelaram que o crescimento e qualidade foram melhores quando a umidade estava na metade superior do limite P. W. P. (ponto de murchamento), quando a água no solo cai abaixo dêsse limite o crescimento da alface é prejudicado e então obtêm-se plantas de crescimento menor, fôlhas menores e cabeças pequenas. Em nosso meio não se procurou ainda, para essa culiura, estabelecer a quantidade necessária para os diferentes tipos de solos e épocas do ano. E' comum indicar desde 3 até 10 litros por metro quadrado, como suficientes para esta planta.

A fim de esclarecer alguns pontos a respeito da quantidade de água necessária, estabeleceu-se o presente ensaio que terá sua continuaçãu.

\section{MATERIAL E MÉTODOS}

O ensaio foi estabelecido na horta da Secção Técnica de Horticultura da E. S. A. "Luiz de Queiroz". O terreno é uniforme e do tipo ferrugínio-argiloso, conhecido como terra roxa.

A variedade utilizada foi a Gorga "Batavia Bionda", por ser a que melhor se comporta em quase todos os meses do an nas condições de clima de Piracicaba e de grande parte do território Paulista.

A água utilizada foi a proveniente do ribeirão Piracicamirim, que atravessa as terras pertencentes à Escola. A irriga ção foi feita por meio de regadores, muito embora a horta possua instalações de irrigação por aspersão ou infiltração. A razão do emprêgo de regadores, foi exclusivamente para se ter idéia exata da quantidade recebida em cada tratamento.

Os canteiros, que possuem as dimensões de $20 \times 20$, receberam todos igual quantidade de adubos orgânicos e minerais e foram repartidos em parcelas de $2 \times 2 \mathrm{mts}$. 
Os tratamentos foram em número de oito distribuidos em três grupos:

\section{QUADRO I}

\begin{tabular}{|c|c|c|c|c|}
\hline Grupo & $\begin{array}{l}\text { Quantidade } \\
\text { total água }\end{array}$ & Hora de irrigação & $\begin{array}{l}\text { Emprêgo Salitre } \\
\text { cada três dias }\end{array}$ & $\begin{array}{l}\text { Pêso médio } 10 \\
\text { plantas em grama }\end{array}$ \\
\hline A & $\begin{array}{r}5 \\
10 \\
15 \\
\end{array}$ & $\begin{array}{ll}\dot{A} & \text { tarde } \\
\dot{A} & \text { tarde } \\
\ddot{A} & \text { tarde }\end{array}$ & - & $\begin{array}{l}4.120 \\
4.248 \\
4.518 \\
\end{array}$ \\
\hline$B$ & $\begin{array}{l}-\overline{10} \\
15\end{array}$ & $\begin{array}{c}\text { Cedo-tarde } \\
5+5 \\
7,5+7,5\end{array}$ & - & $\begin{array}{l}3.960 \\
4.223\end{array}$ \\
\hline $\mathrm{C}$ & $\begin{array}{r}5 \\
10 \\
15\end{array}$ & $\begin{array}{l}\text { A tarde } \\
\text { A talce } \\
\text { A tarde }\end{array}$ & $\begin{array}{l}0,1 \% \\
0.1 \% \\
0,1 \%\end{array}$ & $\begin{array}{l}4.300 \\
4.480 \\
4.690\end{array}$ \\
\hline
\end{tabular}

Grupo A) com 5 litros, 10 litros e 15 litros, empregados à tarde. Grupo B) êste foi subdividido em duas doses; sendo metade empregada pela manhã e a outra à tarde. No primeiro tratamento usaram-se 5 litros de manhã e 5 litros à tarde, perfazendo um total de 10 litros diários. No segundo caso utilizaramse 7,5 cedo e 7,5 à tarde, num total diário de 15 litros. Não foi empregada aqui a dose mínima, isto é, 2,5 cedo e 2,5 à tarde, para dar quantidade total de 5 litros, igual ao primeiro tratamento. Grupo C) êste grupo foi igual ao grupo A, com a única diferença de que recebeu, cada 3 dias, uma dose suplementar de Salitre do Chile (Nitrato de sódio) na proporção de $0,1 \%$ com o fim de se observar sua influência no crescimento da alface e se possível de reduzir pelo seu emprêgo a quantidade de água.

Feita a semeadura em 30-8-1956, realizou-se a transplantação em 30-9-56 e a colheita e pesagem se efetuaram em 13-11-56. As mudas foram distribuidas em 6 linhas distanciadas entre sí de $30 \mathrm{~cm}$ sendo o espaçamento nas linhas também de $30 \mathrm{~cm}$. Fizeram-se 4 repetições dos 8 tratamentos estudados.

Ocorrências: Durante o ciclo vegetativo, foram registradas as chuvas caídas no mês de outubro e consequentemente suspensas as regas, nos seguintes dias : 11, 12, 23, 28 e 30 , com respectivamente $28,12,15,9,6,4$ e $8,8 \mathrm{~mm}$. 


\section{ANALISE DOS RESULTADOS}

Os resultados obtidos são dados a seguir, os quais foram analisados pelo Docente-livre da Cadeira de Matemática, Dr. F. PIMENTEL GOMES, a quem agradecemos a colaboração prestada.

\section{Análise de Variância}

QUADRO II

\begin{tabular}{l|r|r|r|r|r}
\hline \multicolumn{1}{c|}{ Causa de Variação } & G. L. & S. Q. & Q. M. & Êrro & ध \\
\hline Blocos & 3 & 337.384 & & & \\
Tratamentos & 7 & 1.544 .822 & 220.689 & 469,8 & $2,56 \mathrm{xxx}$ \\
Resíduo & 21 & 705.241 & 33.583 & 183,3 & \\
\hline \multicolumn{1}{c}{ Total } & 31 & 2.587 .447 & & & \\
\hline
\end{tabular}

Os graus de liberdade para tratamentos podem ser repartidos como a seguir :

\section{QUADRO III}

\begin{tabular}{l|c|c|c|c|c}
\hline \multicolumn{1}{c|}{ Causa de Variação } & G. L. & S. Q. & Q. M. & Êrro & \multicolumn{1}{|c}{$\vartheta$} \\
\hline Entre grupos : & 2 & 776.659 & 386.330 & 621,6 & $3,39 \times x x$ \\
Dentro do grupo A & 2 & 329.550 & 164.775 & 405,9 & $2,21 \mathrm{x}$ \\
Dentro do grupo B & 1 & 137.813 & 137.813 & 371,2 & 2,03 \\
Dentro do grupo C & 2 & 304.800 & 152.400 & 390,3 & $2,13 \mathrm{x}$ \\
\hline Tratamentos & 7 & 1.544 .822 & & & \\
\hline
\end{tabular}

A comparação entre grupos é prejudicada pelo fato de no grupo B faltar o tratamento com 5 litros de água por metro quadrado por dia. As comparações dentro de $\mathrm{A}$ e $\mathrm{C}$ podem ser melhoradas como se segue:

\section{Dentro do Grupo A \\ QUADRO IV}

\begin{tabular}{l|c|c|c|c|c}
\hline Causa de Variação & G. L. & S. Q. & Q. M. & Êrro & \multirow{2}{*}{ १ } \\
\hline Regressão linear & 1 & 316.013 & 316.013 & 562,2 & $3,07 \times x$ \\
Regressão quadrática & 1 & 13.538 & 13.538 & 116,4 & 0,64 \\
\hline Dentro do grupo A & 2 & 329.551 & & & \\
\hline
\end{tabular}




\section{Dentro do Grupo C}

\section{QUADRO V}

\begin{tabular}{l|c|r|r|r|r}
\hline Causa de Variação & G. L. & S. Q. & Q. M. & Erro & $\vartheta$ \\
\hline Regressão linear & 1 & 304.200 & 304.200 & 551,1 & $\mid 3,01 \times x$ \\
Regressão quadrática & 1 & 600 & 600 & 24,5 & 0,13 \\
\hline Dentro do grupo C & 2 & 304.800 & & & \\
\hline
\end{tabular}

As médias são :

$\begin{array}{lll}\text { Grupo A }(4295+53 \mathrm{~g} & (5 \text { litros } & 4120 \pm 92 \mathrm{~g} \\ & (10 \text { litros } & 4248 \pm 92 \mathrm{~g} \\ \text { Grupo B }(4091+65 \mathrm{~g} & (5 \text { litros } & 4518 \pm 92 \mathrm{~g} \\ & (7,5+7,5 & 3960 \pm 92 \mathrm{~g} \\ & (5 \text { litros } & 4223 \pm 92 \mathrm{~g} \\ \text { Grupo C (4490 + 53g } & (10 \text { litros } & 4400 \pm 92 \mathrm{~g} \\ \text { Agua com 0,1\% de S. do Chile (15 litros } & 4690 \pm 92 \mathrm{~g}\end{array}$

Das análises de variâncias e das médias observadas conclui-se, pois, que o pêso dos pés de alface cresce linearmente nos grupos $\mathrm{A}$ e $\mathrm{C}$. No grupo $\mathrm{B}$ provàvelmente se dá o mesmo, mas a falta de dose menor de água trouxe menor precisão à comparação, de sorte que o valôr de $\vartheta$ obtido $(2,03)$ não atinge o limite de $5 \%$, que é 2,08 . Tendo em vista porém, os resultados dos outros grupos, devemos aceitar também que no grupo $\mathrm{B}$ cresce o pêso do pé de alface com a quantidade de água de rega.

Para comparar melhor os grupos A, B e C, consideramos, a seguir só as doses de 10 e 15 litros, obtivemos então os resultados seguintes:

\begin{tabular}{|c|c|c|c|c|c|}
\hline Causa de Variação & G. L. & S. Q. & Q. M. & Erro & 19 \\
\hline $\begin{array}{l}\text { Quantidade de água } \\
\text { Grupos } \\
\text { Interação }\end{array}$ & $\begin{array}{l}1 \\
2 \\
2\end{array}$ & $\begin{array}{r}367.538 \\
985.658 \\
4.275\end{array}$ & \begin{tabular}{|r|}
367.538 \\
492.829 \\
2.138
\end{tabular} & $\begin{array}{r}606,2 \\
702,0 \\
46,2\end{array}$ & \begin{tabular}{|l|}
$3,31 x$ \\
$3,83 x x$ \\
0,25
\end{tabular} \\
\hline Tratamentos & 5 & $\overline{1.357 .471}$ & & & \\
\hline
\end{tabular}

Podemos ainda separar os 2 graus de liberdade para grupos. 


\begin{tabular}{l|c|c|c|c|c|}
\hline \multicolumn{1}{c|}{ Causa de Variação } & G. L. & S. Q. & Q. M. & Érro & ") \\
\hline A contra B & 1 & 339.306 & 339.306 & 582,5 & $3,18 \times x$ \\
A e B contra C & 1 & 646.352 & 646.352 & 804,0 & $4,39 \times x x$ \\
\hline
\end{tabular}

Estes resultados, combinados com as médias acima indicadas, nos mostraram que os grupos diferem todos entre sí, sendo porém o pior processo no presente ensaio, o de regar duas vêzes por dia, com metade da dose cada vez e sem salitre, e o melhor dos três foi o de regar diàriamente à tarde e com salitre adicionado à água em cada três dias.

\section{DISCUSSAO DOS RESULTADOS}

O presente estudo teve por finalidade conhecer a exigência em água na cultura da alface em solos de tipo argiloso. Como não existisse uma indicação mais ou menos precisa sôbre a quantidade de água necessária para o bom desenvolvimento das plantas, iniciamos a presente investigação.

Os livros e mesmo os práticos indicam doses diárias de água que variam de 5 a 10 litros. Outros apontam que duas regas diárias com o emprêgo da metade em cada urna é mais vantajoso. Aplicamcs dissolvida, uma dose de nitrato de sódio na proporção de $0,1 \%$ cada 3 dias, a fim de verificar o seu efeito em relação às quantidades de água utilizadas.

Os tratamentos foram em número de 8 , distribuidos em 3 grupos: A, B e C. Pela análise estatística dos pesos de cada tratamento, pode-se verificar (Quadro II) que à medida que se aumentava a quantidade de água, havia aumento de pêso das alfaces, de modo que os tratamentos foram altamente significativos, como era de se esperar.

Em seguida para se ter melhor idéia da ação da água e do salitre, procedeu-se à comparação, entre os três grupos estuda$\operatorname{dos} \mathrm{A}, \mathrm{B}$, e C (Quadro III). Pelo quadro pode-se verificar que nos grupos A e $\mathrm{C}$ os resultados foram estatísticamente significativos para o limite de $5 \%$. Dentro do grupo B, os resultados não foram estatisticamente significativos, mas quase atingiram o nível de significância. Talvez a falta do tratamento menor $(2,5+2,5)$ litros afetasse os resultados.

Em seguida (Quadro IV) procedeu-se à comparação entre os três grupos, porém, eliminou-se a dose mínima dos grupos A e C (5 litros) para se ter idéia melhor do comportamento das plantas com os tratamentos restantes. Nota-se pelo (Quadro 3) 
que os resultados foram altamente significativos para os grupos, bem como para a quantidade crescente de água.

$\mathrm{Na}$ comparação entre grupo A contra o $\mathrm{B}$, nota-se que $\mathrm{A}$ apresentou resultado superior ao $B$; o mesmo se deu com $\mathrm{A}$ e B contra C. Sendo êste superior aos dois primeiros, como não poderia deixar de ser, pois recebia além de água um suplemento de nitrato de sódio. A única dúvida suscitada se refere ao grupo B, cujos resultados mostraram-se desfavoráveis em relação ao conceito geral. Poder-se-ia atribuir à evaporação excessiva, devido à temperatura elevada, a causa do menor efeito da água aplicada em doses fracionadas.

\section{CONCLUSÃO}

1) Pelos resultados obtidos, verificou-se que as doses de 5 e 10 litros por metro quadrado, normalmente indicadas, são insuficientes para provocar o desenvolvimento contínuo e rápido da alface.

2) Regas divididas em 2 aplicações, uma pela manhã e outra à tarde, sendo metade da dose em cada uma, não deram resultados esperados.

3) A causa de não ser significativa a subdivisão das regas do item 2, não poude ser suficientemente esclarecida, mas julgamos que uma das razões seria a elevada evaporação durante o dia, nos meses em que o ensaio foi estabelecido, prejudicando o desenvolvimento.

4) Os melhores resultados foram obtidos com aplicação de 15 litros de água por dia e por metro quadrado.

5) Quando se empregou nitrato de sódio em regas, à razão de $0,1 \%$, obtiveram-se maiores rendimentos em relação aos demais.

6) Os gastos em emprêgo de nitrato de sódio compensam sobremaneira, pois, além de se reduzir o volume de água a ser utilizada, o início do corte pode ser antecipado de 15 dias em relação às plantas que não receberam.

7) $O$ presente ensaio demonstrou ainda que as quantidades empregadas não atingiram o máximo, pois pela análise de variância e das médias observadas o pêso dos pés de alface cresce linearmente, no intervalo estudado permitindo aplicação mais abundante de água. 


\section{ABSTRACT}

The author carried out an experiment of watering of lettuce (Lactuca sativa L.) in the vegetable garden of the Escola Superior de Agricultura "Luiz de Queiroz", with soil of the type know as "terra roxa". Eight treatments, with 4 replications, were used, divided into 3 groups, as follows :

Group A - Watering once a day, late, in the afternoon, with 5,10 and 15 liters per square meter;

Group B - Watering twice a day, with 10 and 15 liters per square meter, one half in the morning, one half late in the afternoon;

Group C - Watering as in group A, but with a $0.1 \%$ Chilean nitrate of soda, every 3 days.

The size of plots was $2,0 \times 2,0$ meters.

The means obtained, with their respective standard errors, were the following:

$\begin{array}{ll}\text { Group A - } & \\ \text { (4295 } \pm 53 \text { gm.) } & \\ 5 \text { lit./ sq. m. } & 4120 \pm 92 \mathrm{gm} . \\ 10 \text { lit./ sq. m. } & 4248 \pm 92 \mathrm{gm} . \\ 15 \text { lit./ sq. m. } & 4518 \pm 92 \mathrm{gm} . \\ \text { Group B } . & \\ \text { (4091 } \pm 65 \text { gm.) } & \\ 10 \text { lit./ sq. m. } & 3960 \pm 92 \mathrm{gm} . \\ 15 \text { lit./ sq. m. } & 4223 \pm 92 \mathrm{gm} . \\ \text { Group C } & \\ \text { (4490 } \pm 53 \text { gm.) } & \\ 5 \text { lit./ sq. m. } & 4300 \pm 92 \mathrm{gm} . \\ 10 \text { lit./ sq. m. } & 4480 \pm 92 \mathrm{gm} . \\ 15 \text { lit./ sq. m. } & 4690 \pm 92 \mathrm{gm} . \\ \end{array}$

Differences between groups, as well as within them were significant, even if within groups $B$ the $5 \%$ probability level was not quite reached.

\section{BIBLIOGRAFIA}

ANDERSON E. M., 1939 - Variation in Watertable and soil moisture content of Peat soil Due to Growth of Lettuce. Proc. Amer. Soc. for. Hort. Sci, 37: 693-696.

KNOTT J. E., 1951 - Palestras sôbre Horticultura - Edição da Reitoria da Universidade de São Paulo, pp. 1 - 213. 